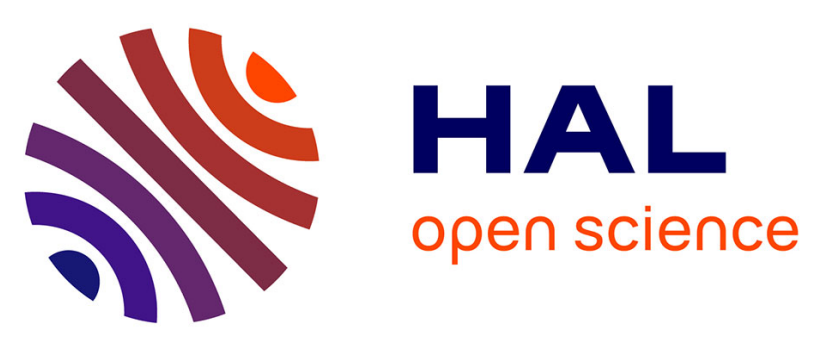

\title{
Just In Time Control of Timed Event Graphs: Update of Reference Input, Presence of Uncontrollable Input
} Eric Menguy, Jean-Louis Boimond, Laurent Hardouin, Jean-Louis Ferrier

\section{To cite this version:}

Eric Menguy, Jean-Louis Boimond, Laurent Hardouin, Jean-Louis Ferrier. Just In Time Control of Timed Event Graphs: Update of Reference Input, Presence of Uncontrollable Input. IEEE Transactions on Automatic Control, 2000, 45 (11), pp.2155-2159. hal-00844944

\section{HAL Id: hal-00844944 \\ https://hal.science/hal-00844944}

Submitted on 16 Jul 2013

HAL is a multi-disciplinary open access archive for the deposit and dissemination of scientific research documents, whether they are published or not. The documents may come from teaching and research institutions in France or abroad, or from public or private research centers.
L'archive ouverte pluridisciplinaire $\mathbf{H A L}$, est destinée au dépôt et à la diffusion de documents scientifiques de niveau recherche, publiés ou non, émanant des établissements d'enseignement et de recherche français ou étrangers, des laboratoires publics ou privés. 


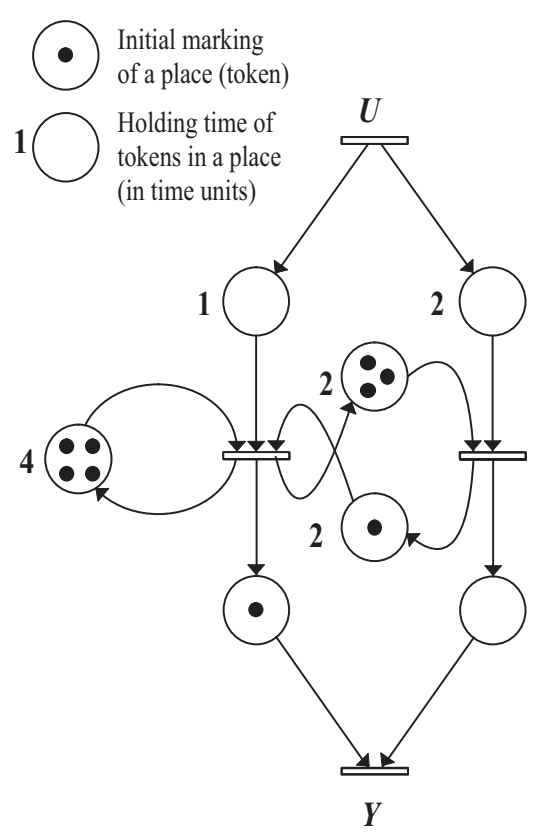

Figure 1: A timed event graph

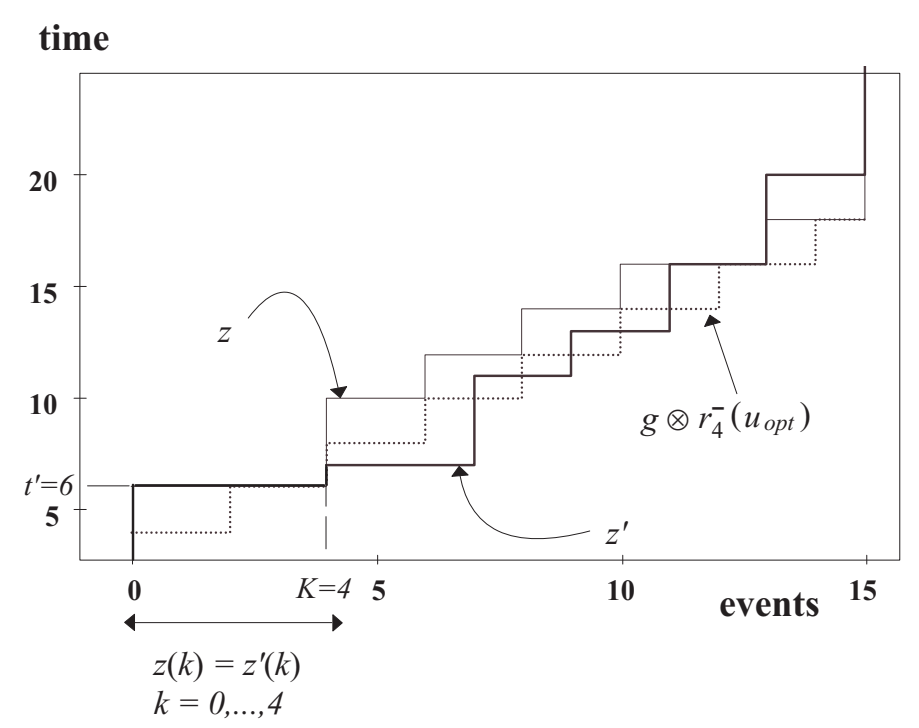

Figure 2: Reference input $z$ (thin line), $z^{\prime}$ (thick line) and $g \otimes r_{4}^{-}\left(u_{\text {opt }}\right)$ (dotted line)

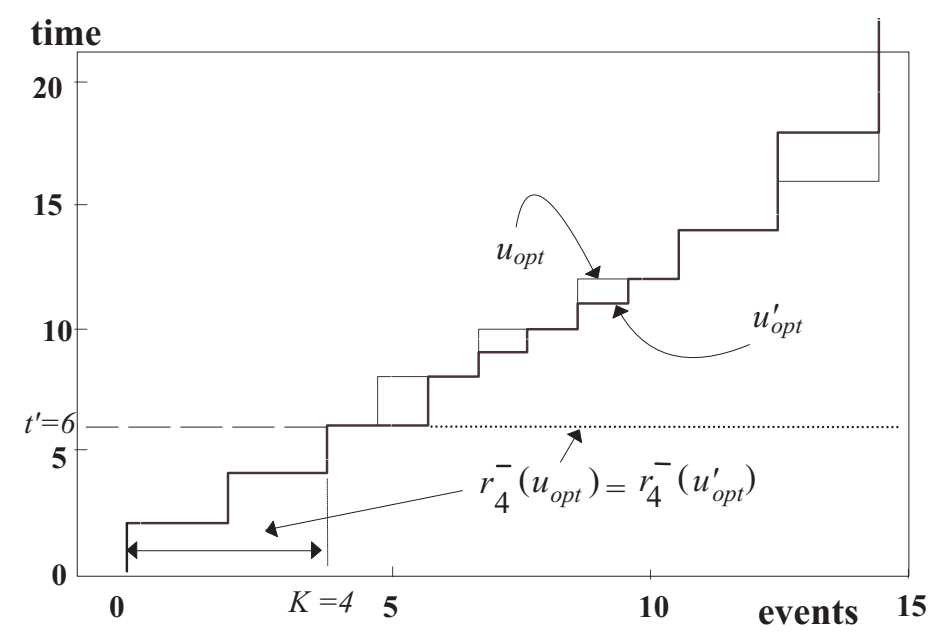

Figure 3: Controls $u_{\text {opt }}$ (thin line), $u_{\text {opt }}^{\prime}$ (thick line) and $r_{4}^{-}\left(u_{\text {opt }}\right)$ (dotted line)

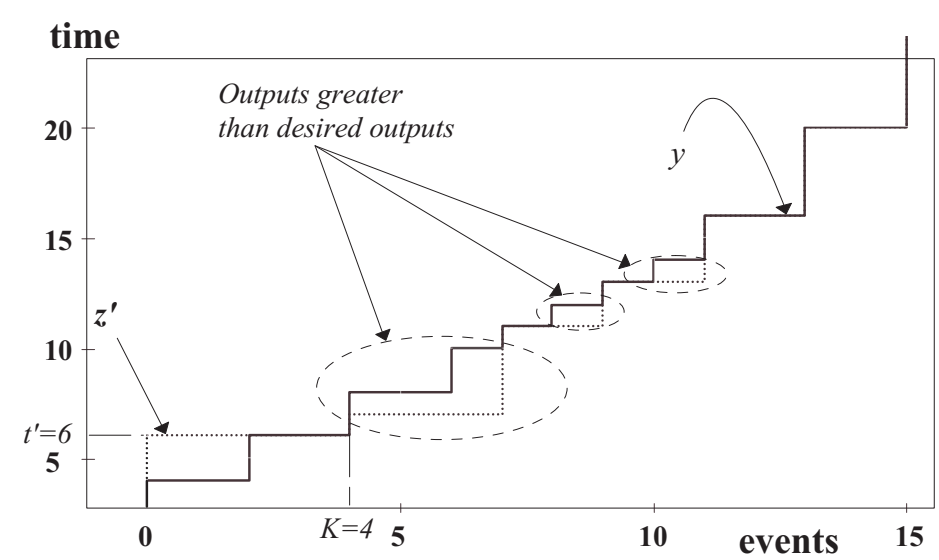

Figure 4: Output $y$ (thin line) and reference input $z^{\prime}$ (dotted line) 